\title{
The determination of the rolling resistance coefficient of a passenger vehicle with the use of selected road tests methods
}

\author{
Bartłomiej Pałasz ${ }^{1}$, Konrad J. Waluś ${ }^{2 *}$, and Łukasz Warguła ${ }^{2}$ \\ ${ }^{1}$ Alumnus Poznań University of Technology \\ ${ }^{2}$ Poznań University of Technology, Piotrowo 3, 60-965 Poznań, Poland
}

\begin{abstract}
Wide range of laboratory and road methods of determining the rolling resistance coefficient impose the need to find an effective way of its estimation. The obtained values of this coefficient differ depending from the assumed calculation model and influence the quality and quantity assessment of cooperation processes between tire and surface. The article presents two experimental methods of determining the rolling resistance coefficient. Road tests were carried out with the use of coast-down and free-rolling method. For each of the road methods the value of the rolling resistance coefficient was determined in three ways. It allowed to compare the selected research methods and calculation methods with the values available in literature.
\end{abstract}

Keywords: rolling resistance coefficient, car transport, coast-down test, research methodology, free rolling from a slope, car tires

\section{Introduction}

The first construction of passenger vehicles were equipped in wheels without tires. In 1895 it was proved that pneumatic car tire can reduce shocks and vibrations and in 1898 the vehicle „Jamais Contente” was equipped in Michelin tires [1-3]. The greatest development in car construction was in 20th century which was caused by a sudden civilization progress, especially after World War 2 [1-4]. The designed vehicle were characterized by a high energy consumption. In order to reduce this factor, innovations in car constructions were introduced, which also contributed to changes in tire constructions and changes in rubber mixtures. The aim of these changes was to limit the rolling resistance coefficient of vehicles. The value of the rolling resistance coefficient is changeable and depends on the exploitation conditions.

In urban cycle the rolling resistances contribute to $46.6 \%$ of total motion rolling resistance [4]. When a vehicle moves at a speed of about $90 \mathrm{~km} / \mathrm{h}$, the value of the rolling resistance coefficient goes down to $37.5 \%$, whereas at the constant speed of $120 \mathrm{~km} / \mathrm{h}$ the value is about $25 \%$ [5]. While driving on a hardened surface the rolling resistance [6]:

\footnotetext{
* Corresponding author: konrad.walus@put.poznan.pl

Reviewers: Marian Dudziak, Mariana Pajtášowá
} 
- increases with an increasing speed,

- increases with the tire deflection which is higher when the tire pressure is lower,

- increases while high torque transmission as the circumferential deformations of the tire increase. It concerns cars with high powered engines,

- decreases with tread-wear.

The article presents the issues of the rolling resistance as a function of the influence of research methods on the value of the obtained rolling resistance coefficient of a vehicle. The laboratory method with the use of roller test bench was described in article [5].

\section{Research methodology of the rolling resistance - road tests}

\subsection{Measurement methodology for the coast-down test method}

In order to carry out research with the use of road tests it is necessary to have a vehicle equipped with wheels and tested tires [5]. Coast-down test method is relied upon a rule of momentum the research car/object to a given speed and then to lose speed due to the rolling resistances. This method is effective when performed at lower speeds up to $20 \mathrm{~km} / \mathrm{h}$ which enables to omit the air resistance. The research should be performed on an even surface in favourable environmental conditions. The research car must have correct wheel alignment and in working order. The measurements may be interfered with: car suspension geometry, Wheel alignment, road gradient, brake dragging, transmission resistance and the loses connected with the work of suspension system of the vehicle [5].

The research was carried out on a horizontal road of a very high quality asphalt. There were 10 trails for the measurement route. The length of the coast-down was defined, the distance of the road on which the driver was to stabilize the speed of the car at $20 \mathrm{~km} / \mathrm{h}$. After obtaining the set speed the car was put on an idle gear and the vehicle was rolling freely losing speed until it stopped. The length of distance of free rolling was measured with the use of tape measure.

The rolling resistance coefficient after carrying out the road tests with the coast-down test can be determined using three mathematical models -3 methods.

\section{Method 1. Method resulting from geometrical measurements}

When coast-down starts, total kinetic energy of a car is converted into work in order to overcome the rolling resistance. After measuring the distance from free rolling of the vehicle till it's stopped using the conservation of energy equation (1) it is possible to determine the value of the rolling resistance coefficient from the following relation [7]:

$$
\frac{m \cdot v_{2}}{2}=m \cdot f_{t} \cdot g \cdot S_{t} \quad \rightarrow \quad f_{t}=\frac{v^{2}}{2 \cdot g \cdot S_{t}}
$$

where:

$v$ - speed of a car when coast-down started $[\mathrm{m} / \mathrm{s}]$,

$g$ - standard gravity $\left[\mathrm{m} / \mathrm{s}^{2}\right]$,

$S_{t}$ - coast-down distance [m].

\section{Method 2. Method resulting from determining a surface area under a diagram}

This measurement is based on the use of measurement device ADIS 16385. The use of measurement equipment allowed to determine the characteristics of vehicle motion kinematics. Second method is relied upon determining the distance of a road covered by the 
vehicle by calculating a surface area of a triangle under the speed diagram. The transient states were omitted in the characteristics. It was assumed that the time that describes the coast-down of the car is the one during which the speed of the car lowers from 80 down to $10 \%$ of its maximum speed. As the speed during coast-down decreases linearly, this range was lineated and defined by the equation of a straight line [7]. A sample diagram of the obtained speed is shown in Figure 1.

The characteristics of a car coast-down $\mathrm{Vx}(\mathrm{t})$

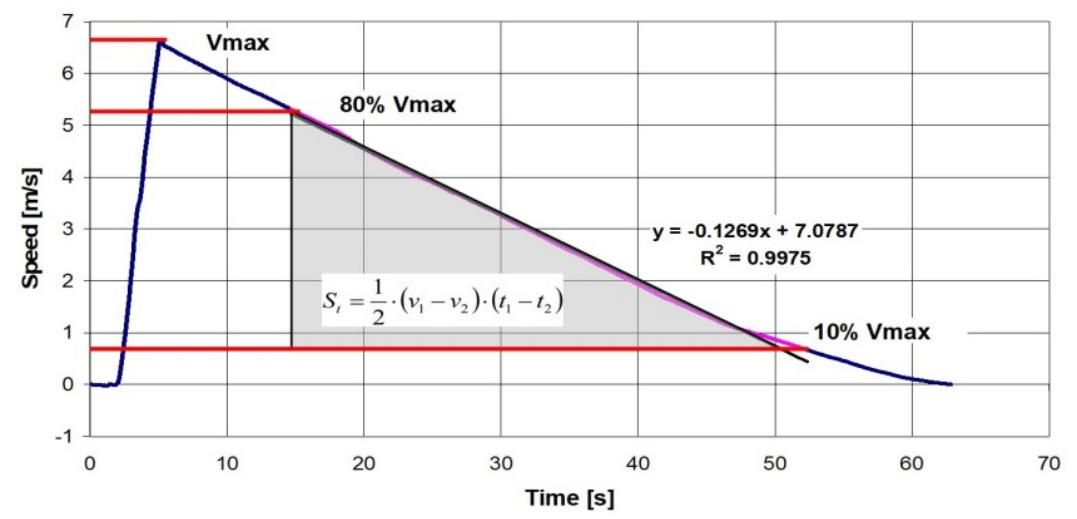

Fig. 1. Speed characteristics of a vehicle for the coast-down test method

\section{Method 3. Method resulting from determining the speed characteristics inclination}

The value of the rolling resistance coefficient can be also determined from the general equation (2) or vehicle motion [7]:

$$
F_{n}=F_{t}+F_{p}+F_{w}-F_{b}+F_{u}
$$

where:

$F_{n}$ - Total motion resistance force,

$F_{t}$ - rolling resistance force,

$F_{p}$ - air resistance force,

$F_{w}$ - elevation resistance force,

$F_{b}$ - inertia resistance force,

$F_{u}$ - transmission resistance force.

The propulsion force equals zero while carrying out the coast-down tests. For low motion speeds on an even flat surface the only resistances to overcome are the rolling resistance and inertia resistance. The values of other resistances approximate zero and can be omitted (3), then [7]:

$$
F_{b}=F_{t},
$$

where:

$$
\begin{aligned}
& F_{b}=m \cdot a \cdot \delta, \\
& F_{t}=m \cdot g \cdot f_{t} .
\end{aligned}
$$

Equating both sides $(4,5)$ of the equation we obtained (6) [7]: 


$$
f_{t}=\frac{a}{g} \cdot \delta
$$

where:

$a$ - vehicle delay while coast-down $\left[\mathrm{m} / \mathrm{s}^{2}\right]$,

$g$ - standard gravity $\left[\mathrm{m} / \mathrm{s}^{2}\right]$,

$\delta$ - reduced mass coefficient.

Reduced mass coefficient $\delta$ equals (7):

$$
\delta=1+\delta_{2} \quad \delta_{2}=\frac{4 \cdot I_{k}}{m \cdot r_{d}^{2}},
$$

where:

$I_{k}$ - wheel inertial moment $\left[\mathrm{kgm}^{2}\right]$,

$m$ - actual car mass,

$r_{d}$ - dynamic wheel radius [m].

At low speeds of about $20 \mathrm{~km} / \mathrm{h}$ the dynamic radius equals static radius. For a wheel with a tire size $205 / 55 / \mathrm{R} 16$ the static radius was $0,3 \mathrm{~m}$ and wheel mass $18.75 \mathrm{~kg}$. Wheel inertial moment was $I_{z}=0.84 \mathrm{~kg} \cdot \mathrm{m}^{2}$, and the reduced mass coefficient $\delta=1.024$.

The rolling resistance coefficient is determined by reading from the speed diagram the vehicle motion delay while coast-down test.

\subsection{Measurement methodology for the road test of free rolling from a slope}

In order to carry out the test a road with an elevation is needed that ends with a horizontal sector. The starting pointed is set on the elevation, from which the research vehicle rolls down freely until it loses speed completely and stops. If the elevation is not too steep then the vehicle should not gain speed of more than $20 \mathrm{~km} / \mathrm{h}$, which means that the air resistance can be omitted. The rolling resistance coefficient is determined from the equation of potential energy and the work done. The equation is as follows (8) [5]:

$$
f=\frac{\sum_{1}^{n} l_{i} \cdot \sin \alpha_{i}}{\sum_{1}^{n} l_{i} \cdot \cos \alpha_{i}}
$$

where:

$l_{i}$ - road sectors length measured with a measure tape,

$\alpha_{i}$ - road sectors gradient angles measured with road protractor. 


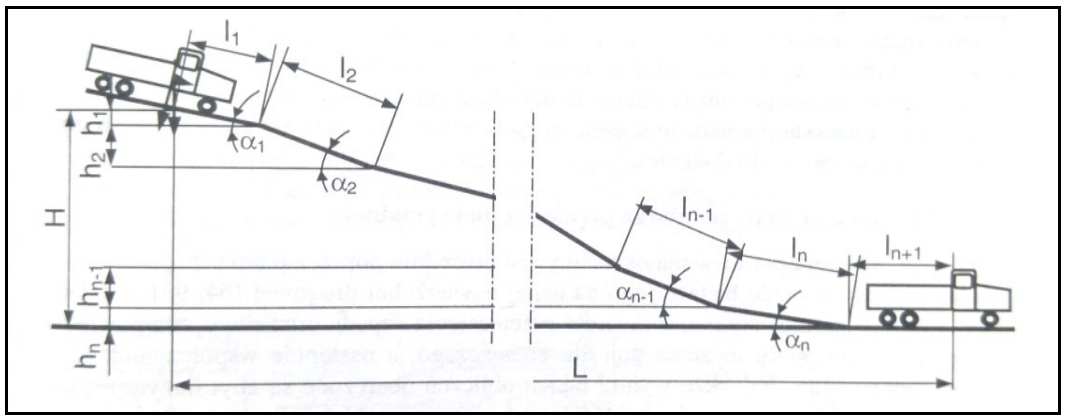

Fig. 2. Measurement road on the elevation [5]: $l_{i}$ - mesurement road sectors lengths $(\mathrm{I}=1 \ldots \mathrm{n})$, $\alpha_{i}$ - measurement road sectors gradient angles $(\mathrm{i}=1 \ldots \mathrm{n}), h_{i}$ - measurement road sectors heights on the elevation, $n+1-$ horizontal sector of the measurement road, $H-$ total height of the measurement road, $L$ - total length of the measurement road

When the elevation is homogeneous in whole of measurement sector then the following equation can be applied (9) [5]:

$$
f=\frac{H}{L},
$$

where :

$H$ - Total height of the measurement road,

$L$ - Total length of the measurement road .

After carrying out the road test with the use of free rolling method the rolling resistance coefficient can be determined on the basis of 3 methods. All three mathematical methods are the same as in the case of determining the rolling resistance coefficient with the use of coast-down test method. It is necessary to determine the road gradient and set the starting point of rolling. The geometrical characteristics of a research surface was defined below and shown in Fig: $l_{1}-4 \mathrm{~m}, l_{2}-31.2 \mathrm{~m}, \alpha_{1}-4^{\circ}, \alpha_{2}-1.5^{\circ}$.

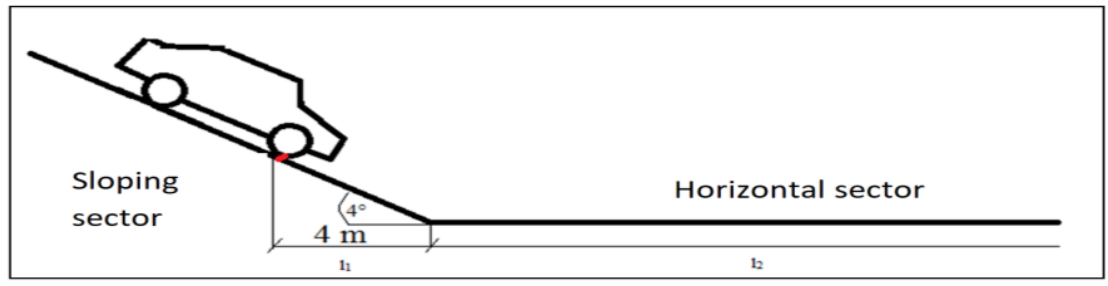

Fig. 3. The elevation diagram on which the vehicle rolling-down method was performed [5]

The rolling resistance coefficient was calculated for both measurement methods and for each of ten research trials.

\section{Vehicle characteristics}

In order to carry out the test the passenger car BMW series 3 E90 model 320d was used. It's a sedan powered by turbocharged Diesel engine of the capacity of $1995 \mathrm{~cm}^{3}$ and 163 hp. The car was produced in 2005 and has rear axis drive. Before the tests tire pressure was checked. The results are presented in Table 1. 
Table 1. The results of tire pressure measurements

Tire pressure for BMW E90

\begin{tabular}{|c|c|c|c|}
\hline Front L & 2.2 & Front R & 2.2 \\
\hline Rear L & 2.2 & Rear L & 2.4 \\
\hline
\end{tabular}

During the tests also the atmospheric conditions were checked Table 2.

Table 2. The measurement results of atmospheric conditions

\begin{tabular}{|c|c|}
\hline Temperature outside & $24^{\circ} \mathrm{C}$ \\
\hline Humidity & $27.2^{\circ}$ \\
\hline Atmospheric pressure & $1008.7 \mathrm{HPa}$ \\
\hline Dew point & $3.7^{\circ} \mathrm{C}$ \\
\hline Road surface temperaure & $28.5^{\circ} \mathrm{C}$ \\
\hline
\end{tabular}

\section{Research results}

\subsection{Research results for the coast-down method}

\section{Method 1. Method resulting from geometrical measurements}

The obtained values of the rolling resistance coefficient are presented in Table 3.

Table 3. Coast-down test method. The rolling resistance coefficient determined from geometrical measurements

\begin{tabular}{|c|c|c|}
\hline No. of trial & Rolling distance & $\begin{array}{c}\text { The value of the rolling } \\
\text { resistance coefficient }\end{array}$ \\
\hline 1 & 183.70 & 0.009 \\
\hline 2 & 148.95 & 0.011 \\
\hline 3 & 146.20 & 0.011 \\
\hline 4 & 145.75 & 0.011 \\
\hline 5 & 134.60 & 0.012 \\
\hline 6 & 147.75 & 0.011 \\
\hline 7 & 159.70 & 0.010 \\
\hline 8 & 163.30 & 0.010 \\
\hline 9 & 142.70 & 0.011 \\
\hline 10 & 144.70 & 0.011 \\
\hline \multicolumn{2}{|c}{ The average value of the coefficient } \\
\hline
\end{tabular}

\section{Method 2. Method resulting from determining a surface area under a diagram}

The obtained values of the rolling resistance coefficient are presented in Table 4.

Table 4. Coast-down test method. The rolling resistance coefficient determined from calculating a surface area under a diagram

\begin{tabular}{|c|c|c|c|c|c|c|}
\hline $\begin{array}{c}\text { No. of } \\
\text { trial }\end{array}$ & $\mathrm{V}_{1}$ & $\mathrm{~V}_{2}$ & $\mathrm{t}_{1}$ & $\mathrm{t}_{2}$ & Surface area & $\begin{array}{c}\text { The value of the rolling } \\
\text { resistance coefficient }\end{array}$ \\
\hline 1 & 5.95 & 0.71 & 51.79 & 9.61 & 110.5116 & 0.016 \\
\hline 2 & 3.44 & 0.46 & 50.48 & 9.30 & 61.3582 & 0.010 \\
\hline 3 & 4.63 & 0.58 & 46.95 & 11.51 & 71.766 & 0.015 \\
\hline 4 & 4.41 & 0.58 & 44.55 & 14.03 & 58.4458 & 0.014 \\
\hline
\end{tabular}




\begin{tabular}{|c|c|c|c|c|c|c|}
\hline 5 & 4.30 & 0.54 & 50.36 & 15.74 & 65.0856 & 0.014 \\
\hline 6 & 4.67 & 0.67 & 52.06 & 15.71 & 72.700 & 0.015 \\
\hline 7 & 4.60 & 0.63 & 55.49 & 13.98 & 82.39735 & 0.013 \\
\hline 8 & 4.96 & 0.71 & 56.59 & 18.56 & 80.81375 & 0.016 \\
\hline 9 & 4.04 & 0.59 & 54.69 & 19.61 & 60.513 & 0.014 \\
\hline 10 & 4.29 & 0.61 & 54.12 & 15.39 & 71.2632 & 0.013 \\
\hline \multicolumn{8}{|c|}{ The average value of the coefficient } & $\mathbf{0 . 0 1 4}$ \\
\hline
\end{tabular}

\section{Method 3. Method resulting from determining the speed characteristics inclination}

The obtained values of the rolling resistance coefficient are presented in Table 5.

Table 5. Coast-down test method. The rolling resistance coefficient determined from the speed characteristics inclination

\begin{tabular}{|c|c|c|}
\hline No. of trial & Rolling distance & $\begin{array}{c}\text { The value of the rolling } \\
\text { resistance coefficient }\end{array}$ \\
\hline 1 & 183.70 & 0.013 \\
\hline 2 & 148.95 & 0.007 \\
\hline 3 & 146.20 & 0.012 \\
\hline 4 & 145.75 & 0.013 \\
\hline 5 & 134.60 & 0.012 \\
\hline 6 & 147.75 & 0.011 \\
\hline 7 & 159.70 & 0.010 \\
\hline 8 & 163.30 & 0.012 \\
\hline 9 & 142.70 & 0.011 \\
\hline 10 & 144.70 & 0.010 \\
\hline \multicolumn{2}{|c|}{ The average value of the coefficient } \\
\hline
\end{tabular}

\subsection{Research results for the method of elevation rolling-down method of a research vehicle}

\section{Method 1. Method resulting from geometrical measurements}

The obtained values of the rolling resistance coefficient are presented in Table 6 .

Table 6. Free rolling-down method. The rolling resistance coefficient determined from geometrical measurements

\begin{tabular}{|c|c|c|}
\hline No. of trial & Rolling distance & $\begin{array}{c}\text { The value of the rolling } \\
\text { resistance coefficient }\end{array}$ \\
\hline 1 & 35.20 & 0.015 \\
\hline 2 & 42.20 & 0.017 \\
\hline 3 & 41.90 & 0.017 \\
\hline 4 & 41.70 & 0.017 \\
\hline 5 & 42.10 & 0.017 \\
\hline 6 & 34.50 & 0.015 \\
\hline 7 & 42.40 & 0.017 \\
\hline 8 & 42.40 & 0.017 \\
\hline 9 & 42.75 & 0.017 \\
\hline 10 & 41.65 & 0.017 \\
\hline \multicolumn{2}{|c|}{ The average value of the coefficient } & $\mathbf{0 . 0 1 7}$ \\
\hline
\end{tabular}




\section{Method 2. Method resulting from calculating a surface area under a diagram}

The obtained values of the rolling resistance coefficient are presented in Table 7.

Table 7. Free rolling-down method. The rolling resistance coefficient determined from calculating a surface area under a diagram.

\begin{tabular}{|c|c|c|c|c|c|c|}
\hline $\begin{array}{c}\text { No. of } \\
\text { trial }\end{array}$ & $\mathrm{V}_{1}$ & $\mathrm{~V}_{2}$ & $\mathrm{t}_{1}$ & $\mathrm{t}_{2}$ & $\begin{array}{c}\text { Pole } \\
\text { powierzchni }\end{array}$ & $\begin{array}{c}\text { The value of the rolling } \\
\text { resistance coefficient }\end{array}$ \\
\hline 1 & 4.24 & 0.53 & 14.25 & 39.28 & 46.4306 & 0.018 \\
\hline 2 & 4.38 & 0.62 & 14.00 & 40.63 & 50.0644 & 0.019 \\
\hline 3 & 4.41 & 0.55 & 14.97 & 41.82 & 51.8205 & 0.019 \\
\hline 4 & 4.60 & 0.51 & 14.28 & 38.31 & 49.1413 & 0.018 \\
\hline 5 & 4.36 & 0.56 & 12.48 & 36.27 & 45.2010 & 0.018 \\
\hline 6 & 4.27 & 0.53 & 13.15 & 39.71 & 49.6672 & 0.018 \\
\hline 7 & 4.49 & 0.56 & 16.48 & 41.96 & 50.0682 & 0.019 \\
\hline 8 & 4.43 & 0.56 & 10.87 & 38.37 & 53.2125 & 0.019 \\
\hline 9 & 4.47 & 0.56 & 15.75 & 41.40 & 50.1457 & 0.019 \\
\hline 10 & 4.40 & 0.56 & 18.37 & 41.32 & 44.064 & 0.018 \\
\hline & \multicolumn{6}{|c|}{ The average value of the coefficient } \\
\hline
\end{tabular}

\section{Method 3. Method resulting from determining the speed characteristics inclination}

The obtained values of the rolling resistance coefficient are presented in Table 8 .

Table 8. Free rolling-down method. The rolling resistance coefficient determined from the speed characteristics inclination

\begin{tabular}{|c|c|c|}
\hline No. of trial & Rolling distance & $\begin{array}{c}\text { The value of the rolling } \\
\text { resistance coefficient }\end{array}$ \\
\hline 1 & 35.20 & 0.015 \\
\hline 2 & 42.20 & 0.014 \\
\hline 3 & 41.90 & 0.015 \\
\hline 4 & 41.70 & 0.015 \\
\hline 5 & 42.10 & 0.017 \\
\hline 6 & 34.50 & 0.015 \\
\hline 7 & 42.40 & 0.016 \\
\hline 8 & 42.40 & 0.015 \\
\hline 9 & 42.75 & 0.016 \\
\hline 10 & 41.65 & 0.018 \\
\hline
\end{tabular}

\section{Result analysis}

After experimental tests and calculations were carried out the average values of rolling resistance were obtained which are presented in Figure 4. 


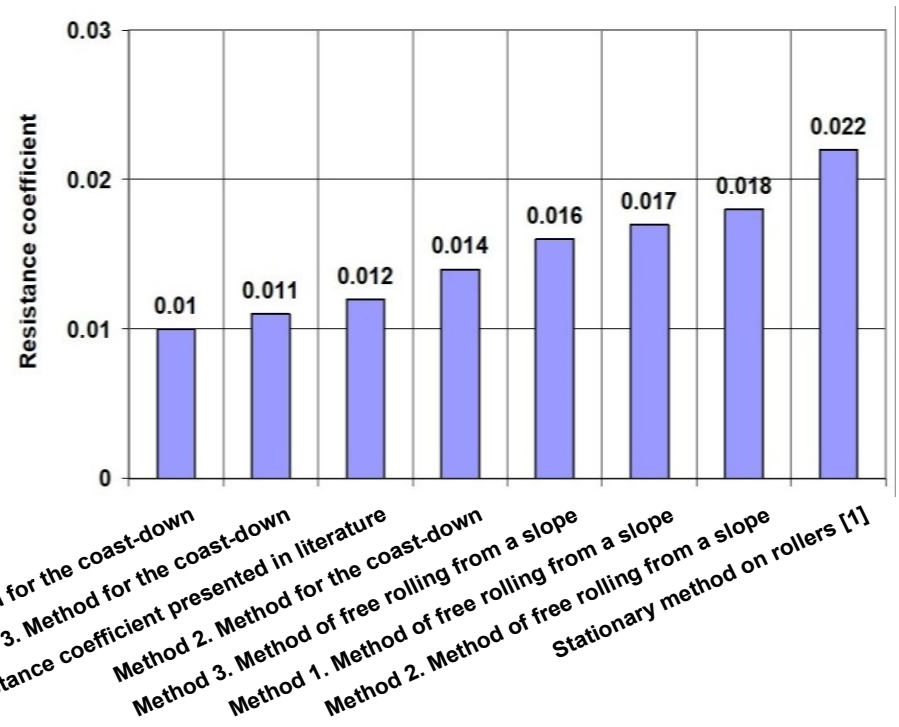

Fig. 4. Record sheet of average values of the rolling resistance coefficient

For a passenger vehicle moving on an asphalt surface, the value of rolling resistance coefficient available in literature is 0.012 . Comparing this value to the obtained results it can be observed that only for the coast-down test method and for $1^{\text {st }}$ and $3^{\text {rd }}$ calculation method the rolling resistance coefficient was similar to the value in literature.

The rolling resistance coefficient of a value similar to the value of coefficient $i$ literature was obtained applying the first calculation model for the coast-down test method. The coefficient of the value of 0.010 was determined using the first method - method of geometrical measurements. The measurement of the covered coast-down distance was measured with measure tape. The most difficult part of this method was to obtain stable initial speed of a research vehicle. As it is difficult to determine the initial speed of the coast-down this method is inaccurate.

The second method included the use of ADIS equipment and determining the covered coast-down distance by calculating triangle surface area under a diagram of speed characteristics. The differences between the values of rolling resistance coefficient obtained and available in literature are slight and may result from the simplification of speed characteristics to the range of $80 \%$ to $10 \%$ of initial speed. The change of surface area under the diagram may have a significant influence on the obtained values.

In method 3 owning to the linearization of the speed characteristics slight changes of speed changes were averaged. This method allows to limit the influence of the measurements inaccuracy. The constant speed of the vehicle at the moment of putting the vehicle on the idle gear is not necessary and low speed fluctuations do not influence the value of the obtained coefficient.

Applying the method of free rolling-down of the vehicle for all calculation methods the obtained values of rolling resistance coefficient were higher as the ones available in literature. Applying this method the greatest obstacle is to find a proper place to carry out road tests. The measurement of the road distance starts when the brake pedal is released and the rolling down starts from an elevation. It is also difficult to determine precisely the angle of the road gradient and setting the point when the rolling-down starts. These factors influence the value of the rolling resistance coefficient significantly thus influencing the obtained results. 
Also the values of rolling resistance coefficient obtained during laboratory tests on a roller bench were compared which was described in article [1]. In this method it is necessary to know the exact load distribution of a research vehicle that influences significantly the obtained value of the rolling resistance coefficient.

The choice of the research method has a huge influence on the value of the obtained rolling resistance coefficient. The coast-down method allowed to determine the rolling resistance coefficient of a value most similar to the one presented in literature. However, pointing the best method is impossible because depending on the interpretation both the highest and lowest values of the rolling resistance coefficient can be obtained.

\section{Summary and conclusions}

In 2015 the number of cars worldwide was 1.1 billion and according to estimations the number will continue to grow [8]. It indicates that the problems of road transport which is the use of natural resources and environment protection are becoming even more important scientific problem. Even the smallest achievement to reduce the motion resistances of the vehicles are vital due to the number of exploited cars. One of the basic resistances is the rolling resistance of the vehicle, influenced by factors connected with the vehicle itself and road surface. Vehicle constructors carry on research connected with new types of tires and systems controlling tire pressure that influence that parameter significantly. Road surface scientists are aiming at obtaining surfaces that will allow for a low rolling resistance coefficient and at the same time high traction coefficient. Combining the results of these two researches that lead to economical and environmental benefits requires the use of varied research methods.

The main aim of this research was the analysis of the influence of research methods on the value of rolling resistance coefficient. The road method of the coast-down test allowed to determine the value of rolling resistance coefficient that was the most similar to the one available in literature. The method of coast-down test can be performed in a very traditional way, which is a distance measurement with the use of measure tape. This method was very efficient, easy to carry out and allowing to obtain coefficient values in accordance with literature.

During the road tests the measurement results can be influenced by many possible measurement failures. In the coast - down test method the greatest influence on the rolling distance of the vehicle had the initial speed of the coast-down. Another factor influencing the obtained results is the state and the quality of the road surface and working order of the vehicle, weather conditions such as outside temperature and wind speed. Increasing the accuracy of the measurements is possible with use of measurement equipment i.e. ADIS 16385.

In rolling-down method of a vehicle form an elevation the initial speed of the research vehicle was zero. The car accelerates after the brake pedal is released, due to which the initial value of the coast-down does not influence the value of the obtained rolling resistance coefficient and the obtained value of maximum speed is repetitive. Applying the method of the vehicle rolling-down from the elevation the biggest problem poses to measure the gradient angle of initial distance, which has a huge influence while calculating the values of the coefficient.

The choice of research method has a huge influence on the value of the obtained rolling resistance coefficient. The coast-down method allowed to determine the rolling resistance coefficient of a value most similar to the one presented in literature. However, pointing the best method is impossible because depending on the interpretation both the highest and lowest values of the rolling resistance coefficient can be obtained. 


\section{References}

1. MICHELIN, Komfort Mechaniczny $i$ Akustyczny. Wydawnictwo Societe de Technologie Michelin, (2002)

2. MICHELIN, Opona przyczepność. Societe de Technologie Michelin, (2002)

3. MICHELIN, Opór toczenia a oszczędność paliwa. Societe de Technologie Michelin,

4. S. Tamyra, Opór toczenia opon samochodowych. Wydawnictwo Politechniki Gdańskiej, Gdańsk, (2007)

5. B. Pałasz, K. J. Waluś. Ł. Warguła, The determination of the rolling resistance coefficient of a passenger vehicle with the use of roller test bench method

6. L. Prochowski, Pojazdy Samochodowe. Mechanika ruchu. Wydawnictwo komunikacji i łączności Warszawa, ISBN 978-83-206-1701-6 (2008)

7. http://www.iepim.pr.radom.pl/dokumenty/BSiTR/Inst\%202.pdf

8. https://www.motofakty.pl/artykul/liczba-samochodow-na-swiecie.html 